\title{
Affinities in the construction techniques of a unitary project: the coastal towers of the Asinara Island (Sardinia)
}

\section{Stefania Murru}

Università degli Studi di Cagliari, Cagliari, Italy, s.murru@inwind.it

\begin{abstract}
This study stems from the idea of highlighting the constructive affinities among the three towers of the Asinara Island, resulting from a unitary construction project. The research methodology identifies a multidisciplinary protocol based on a stratigraphic approach. With the aid of historical sources and petrographic and geochemical investigations, the sequence of the construction phases and stratigraphic units was identified for the towers. The results were compared in order to highlight common elements and significant differences in the typology and proportional relationships between the geometry and the constructive elements. The comparison also included material composition and masonry texture.

The results highlight several similarities among the three towers and confirm the initial thesis: the imprint due to the unitary construction project was of major importance in terms of construction choices and binds the three towers in a common thread.
\end{abstract}

Keywords: masonry techniques, stratigraphy, historical mortars, 3D models

\section{Introduction}

This study is a part of a wider research project aimed at investigating the construction techniques of 16th and 17th century Sardinian coastal towers.

In detail, we decided to analyze the towers of Cala d'Oliva, Cala d'Arena and Trabuccato located on the Asinara Island (Fig. 1), in the North West of Sardinia. Given their specific conditions of isolation up to a relatively recent age, the three towers are an interesting topic for research. In fact, since the towers underwent few changes over the centuries, their historical constructive techniques can still clearly be read.

Specifically, this study aims to:

-identify the construction techniques and technologies, with a special focus on masonry techniques;

-identify and date the different construction phases and restoration works carried out on the towers; -identify and catalogue the types of masonry that can serve as reference for the archaeometric dating (by analogy) of other buildings.

With these aims, we decided to combine contributions from several disciplines, in order to capture different aspects of historical construction techniques while assuming that these buildings could not have been restored without a thorough investigation phase.

\subsection{The Asinara Island fortification}

The towers under examination were conceived on the basis of a unitary project whose realization was assigned to the capomastro, master builder, Girolamo Carta. They were completed in 1610 (Rassu, 2005).

Their construction was part of a wider fortification process involving the Sardinian coast and stemmed from the impetus of the Spanish monarchy that reached its peak in the 
late 16th and early 17th century (Pillosu, 1957; Montaldo, 1992). Indeed, following the defeat of Tunis and Algiers, the Spanish Monarchy had lost two important fortresses that ensured its control of the Western Mediterranean and formed a barrier to the advance of the Ottomans. Therefore, Sardinia took on a crucial role in the new geopolitical Mediterranean asset (Murgia, 2010; Casula 2010).
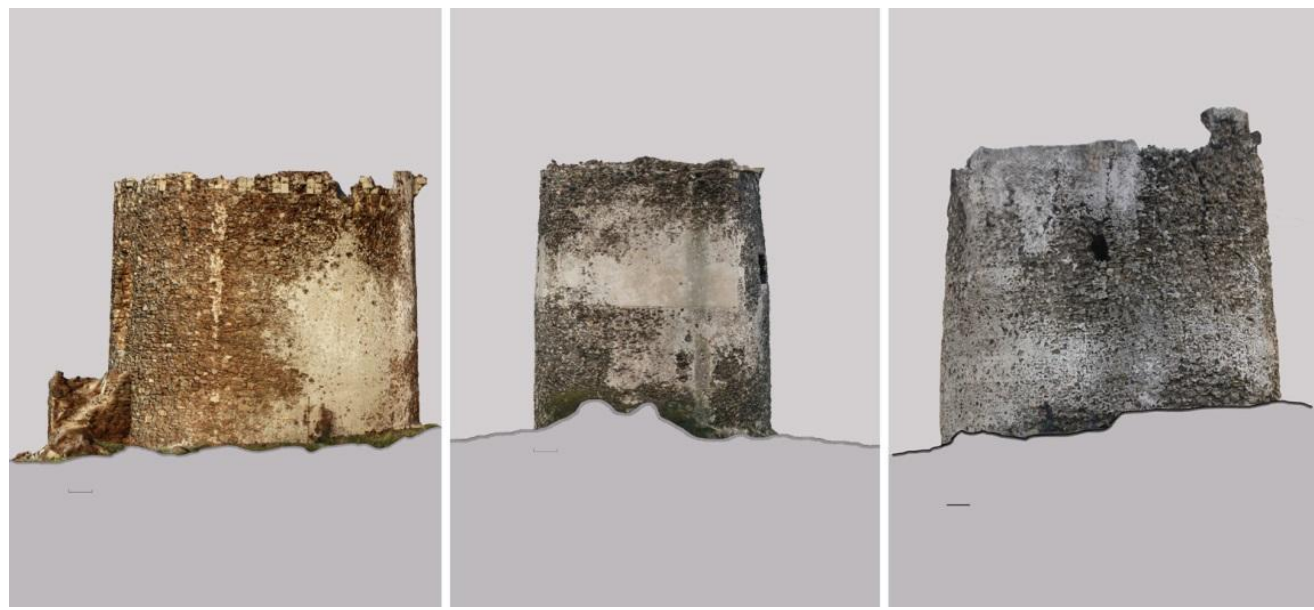

Fig. 1- Orthogonal perspective view of Trabuccato, Cala d'Oliva and Cala d'Arena towers obtained by processing the 3D model (Murru, 2015).

These were the preconditions for developing a static system for the Island's coastal defense which, while including some buildings located in the areas of greatest economic interest, was conceived and structured as a real defense system only in this historical period.

Specifically, the plan for fortifying the Asinara Island came from the need to protect the transit of Spanish, "Italian" and French vessels and provide safe shelter to Christian boats which were in difficulty. The defense system also attracted choral fishing boats, an important economic income for the Kingdom (Rassu, 2005). The small island in fact was a highly interesting geo-strategic location in the commercial routes of this area of the Mediterranean.

Already a few decades after their construction, the three towers were the protagonists of important military events and were severely damaged. Due to serious damage, the Cala d'Arena tower was soon abandoned, while the other two were restored several times during the 18th and 19th century and continued to play their role. Given the particular accessibility conditions and the fact that the island became the home of a high security prison, the three buildings did not undergo substantial changes during the last century, except for the tower of Cala d'Oliva. It was often restored even in recent times (the latest dating back to the 1990s).

Currently, the island belongs to the territory of the Parco Nazionale dell'Asinara, an entity established in 2002 after the high security prison was closed. The three towers are owned by the Regione Autonoma della Sardegna, which by way of a Regional Council Resolution (no. 48/1 2008) ordered their assignment to the Agenzia regionale Conservatoria delle coste, subsequently completed by deed dated 30 March 2009.

\section{The research protocol}

Each case should be treated individually, keeping in mind the geographic, historical and material features of each tower. However, in analyzing the system, we decided to adopt a uniform investigation method that could link the information obtained and compare it more easily. For this reason, a research protocol was 
established which may be fully applied to each tower. It may be summarized in 4 main phases:

- indirect (archival and bibliographical) and direct (on-site) investigation phase

- data processing (material characterization; survey restitution and thematic mapping);

- data management;

- summary of the obtained results.

\subsection{The indirect and direct investigation phase}

The first investigation phase involved the acquisition of data both from historical sources and through direct on-site investigation. The archival and bibliographical sources (Fig. 2) were an important support for directly testing the technical requirements described in the project documents and for identifying the construction phases. It allowed us to carry out a more aware and focused metric and photogrammetric survey.

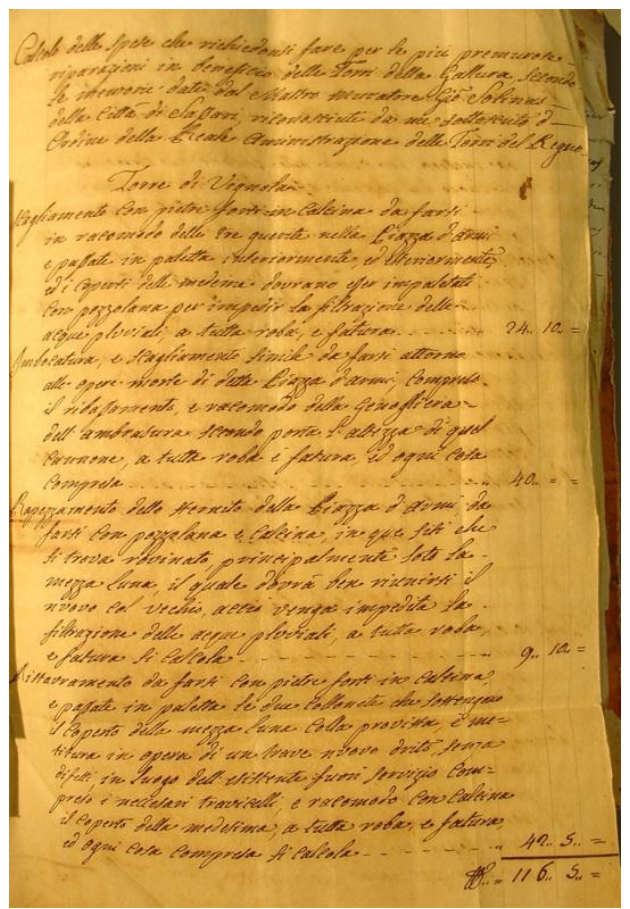

Fig. 2- Archivio di Stato di Cagliari, Amministrazione delle torri (Murru, 2006).

\subsection{Data processing}

For this study, we chose to combine traditional survey methods and techniques based on digital photogrammetry. Starting with an ordered set of photos taken on the basis of specific parameters, we created a textured digital model through automatic detection of homologous points with 123D Catch software. Then, with the aid of a common 3D modeling software, the model was exported, scaled and verified using the measures taken from the direct metric survey (Pisu and Casu, 2013). Thanks to the significantly shorter survey time, this tool allowed us to carry out a systematic investigation of a large number of case studies, including the three towers. Then, using 3D models, we performed more in-depth analytical studies. In detail, we were able to conduct an easier and more comprehensive investigation of the typological features and masonry textures which were analyzed according to archaeometric criteria (Fig. 3).
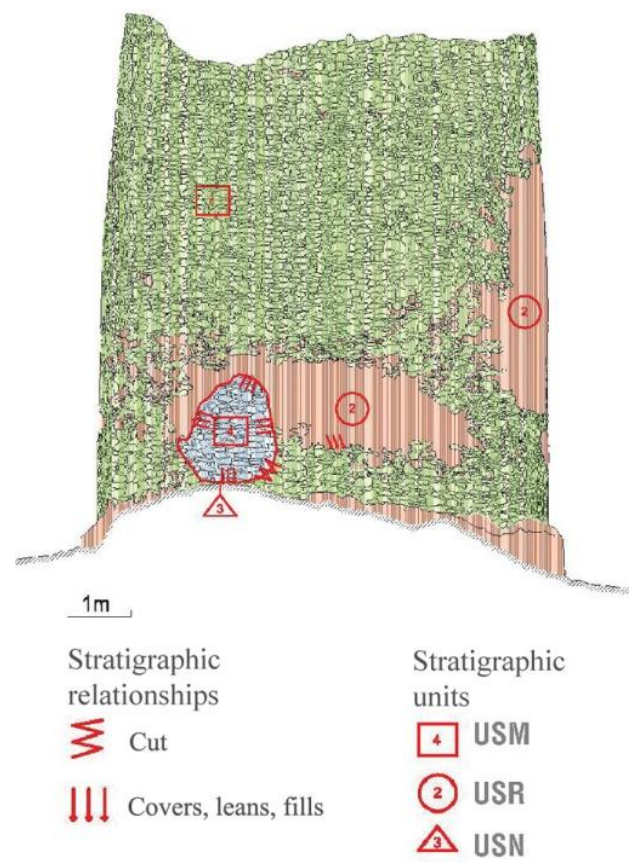

Fig. 3- Cala d'Oliva tower, stratigraphic analysis (Murru, 2014). 
In addition to an archaeometric point of view (Giannattasio, Grillo and Vacca, 2013), the masonries were also studied in terms of material with particular focus on mortar characterization. Petrographic and geochemical investigations of mortar samples were conducted. With regard to material characterization, special emphasis was placed on the historical mortars. In fact, as we can see in several towers, the structural instability of the masonry often depends on mortar breakup (Giannattasio and Grillo, 2013).

Even in this case a protocol was applied which may be summarized in the following steps (Giannattasio and Grillo, 2011; Giannattasio, Grillo and Murru, 2014):

- macroscopic on site analysis, wich leads to the reasoned choice of samples and the first identification of the construction phases;

- execution of photos of the samples with digital camera;

- petrographic analysis of thin section in transmitted light polarized (OM) and X-ray diffraction of samples such as to characterize the mineralogical composition of the aggregates and the binder.

Then it is expected to complete the investigation by:

- disintegration of mortar sample in order to define the size distribution and the proportions of the binder/aggregate;

- X-ray diffraction analysis (XRD).

\subsection{Data management and summary}

The data were subsequently rationalized and systematized for the purpose of creating an abacus of masonry types referring to the tower system. This could be a useful point of comparison for dating other buildings. A database containing general information about the structure and more specific data on building techniques and materials was populated and then georeferenced. This allowed the data to be compared dynamically, accessed more easily and to be continuously added.

\section{Common elements and significant differences in the three towers}

\subsection{Typological and architectural features}

The 3D reconstruction made it possible to perform a more detailed study of the towers from an architectural and typological perspective. This allowed us to appreciate small discrepancies compared to previous categorizations.

From this point of view, the three towers are very similar. All are truncated cone-shaped and very slightly flared (2-7\%). The Trabuccato and Cala d'Arena towers are also very similar in size: they have a diameter of about $13 \mathrm{~m}$ at the base and $12 \mathrm{~m}$ at the top, with an average height of $11 \mathrm{~m}$, and their entrance is located approximately at $5.5 \mathrm{~m}$. Instead, the Cala d'Oliva tower is slightly smaller and more slender, with a base diameter of $10 \mathrm{~m}$ and a height ranging from 9.50 to $12 \mathrm{~m}$. Even the access is higher (about $7 \mathrm{~m}$ ) (Murru, 2014).

Within a logic of saving on construction, the three towers are not provided with decorative elements. However, the crowning features a continuous apparatus of limestone corbels with constant spacing.

Even the distribution of spaces is very similar for the three towers and is the same for the majority of Sardinian towers.

The artifacts are divided into three levels, the first consisting of a full basement that houses the cistern, the second that houses the main room and finally the last level where we find the terrace.

However, in the Trabuccato tower, the main room is vaulted with a dome and a large central column, and a partition wall divides it into two compartments. This partition probably dates back to a later period because the masonry has different characteristics than the rest of the tower. Even the stairs that currently lead to the entrance were built at a later date. In fact, in addition to having different masonry texture and composition, they are extraneous to the defense logic of 16th-17th century towers. Indeed the 
access was overhead and only accessible through retractable stairs. We come to the terrace

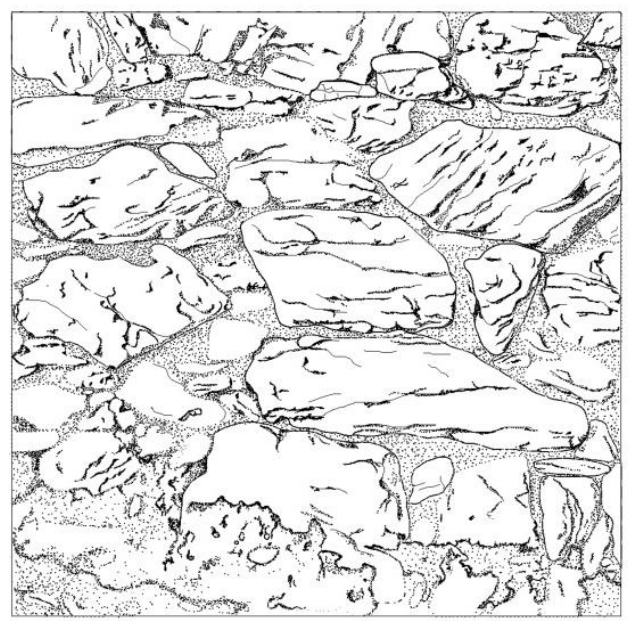

through stairs built into the masonry, covered by juniper beams.

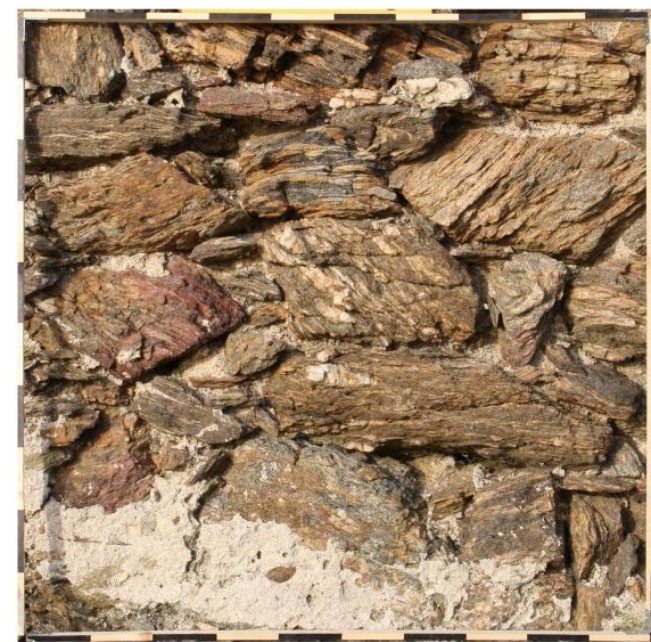

Fig. 4- Masonry sample of Trabuccato tower (Murru, 2014).

In the Cala d'Oliva tower, the main level consists of a single room covered with a dome. Even in this case, the terrace is connected to the main room with stairs built into the masonry. The metal ladder leading to the entrance is evidence of the different functions the tower has had over the centuries and of the fact that it was used until recent times. Perhaps for this reason, the tower is currently in an excellent state of preservation.

It was not possible to enter the Cala d'Arena tower, due to its bad state of preservation. For this reason, a smaller quantity of data was acquired. Unlike the other two towers, it has no basement, but has enormous granite elements placed in its lower part.

It was abandoned during the first half of the 17th century because it was no longer necessary, and displays significant structural instability: two deep symmetrical cracks are probably the reason for the dome collapse and for several gaps that weaken the masonry.

\subsection{Construction techniques and materials}

The three towers have many similarities also in terms of materials and construction techniques. The main building material is mica-schist, directly found on site, while limestone elements were used in the three towers for building the secondary elements such as the doorposts, lintels, corbels and stairs.

In all three cases, the masonry techniques are also very similar. In the Trabuccato tower, we find rubble masonry (Fig. 4) with a thickness of about $250 \mathrm{~cm}$. It consists of two 70-80 cm facings and an internal filling in mortar and small stones. The stone blocks are in mica-schist of medium-large size (25-50 cm wide and 15-20 $\mathrm{cm}$ high); they are unprocessed and organized in "cantieri" with an almost regular thickness of $75-80 \mathrm{~cm}$. The assortment of stone elements is not very varied, but there are many "wedges" and the meshing is quite fine. Limestone appears only in "wedges", in the non-structural elements (the corbels and sentry boxes of the crowning) and in the stratification of the vault; in this case the ashlars are blank, more regular and bigger. The stone elements are organized without taking into account the orientation of the material layers. The joints are relatively thin $(1-2 \mathrm{~cm})$ and deeply eroded. The joint mortar, analyzed in thin section, is well made and this is confirmed by the good condition of the masonry. It shows a quartz-feldspathic aggregate with bimodal character, uniformly distributed (Murru, 2013). 
From observations made through the many gaps of the Cala d'Arena tower, we can assume that the masonry has a thickness similar to the Trabuccato tower $(250 \mathrm{~cm})$. It is a rubble masonry that consists of mica-schist elements of medium size, ordered in "cantieri". Large granite stones appear in the lower part. They act as basement of the tower. The assortment of stone elements is not very varied and the "wedges" probably collapsed due to the strong erosion of the mortar joints. In this case also, limestone appears only in "wedges" in the non-structural elements (the corbels and sentry boxes of the crowning). The stone elements are organized without taking into account the orientation of the material layers. The joints are very irregular and profoundly eroded.

Since the tower was abandoned early, no signs of later interventions can be seen. In fact, from a preliminary macroscopic analysis of the interstitial mortars, we can assume that these are attributable to the construction phase. For this reason, only one sample tower was examined
(CDA 01). It is an interstitial mortar taken from under the entrance (the most degraded part). The binder/aggregate ratio would seem high, although for a more accurate definition of the percentages it would be better to wait for a more detailed investigation. The micritic binder is carbonatic and is probably the same one used in the other towers in this area. The aggregate, which could be defined bimodal classed, has a thin fraction, predominantly silicate, which is associated with fragments of metamorphic rock (polycrystalline) of larger size.

Finally, the masonry in the Cala d'Oliva tower has a slightly smaller thickness (about $200 \mathrm{~cm}$ at the entrance level). As mentioned, the tower is very well preserved. For this reason, it was not possible to survey the masonry section. Consequently, the size of the two walls and the composition of the nucleus were not determined. It consists of mica-schist elements of small size (10-30 $\mathrm{cm}$ wide and 5-15 cm high), unprocessed and rough-hewn only on the visible side.
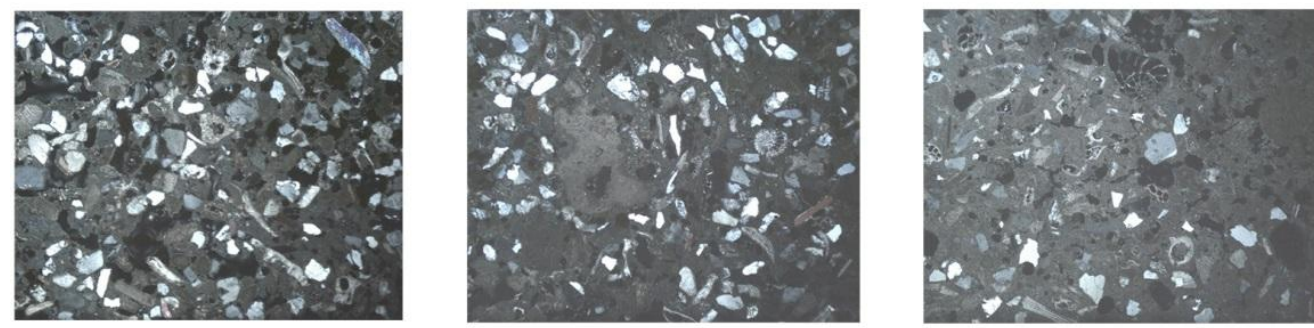

Fig. 5- Thin sections of samples CDO 01, CDO 02, CDO 03 representing three plasters taken from the Cala d'Oliva tower (Grillo, 2013).

The texture is characterized by many "wedges" and the meshing is very fine. The stones are ordered in "cantieri" of about $60 \mathrm{~cm}$. The joints are not regular in size. Due to the difficult exposure conditions, the cladding layers have disappeared almost everywhere, except in the Cala d'Oliva tower. The tower was used until recent times and has undergone several maintenance works over the centuries. The overlapping of interventions has made the stratification of different restoration phases evident. Starting from a 3D reconstruction, we represented the various transformation activities graphically and then ordered them according to a relative chronology. Thanks to the numerous archival and bibliographical sources available, establishing an absolute chronology may be possible.

In this regard, the support provided by the optical microscope analysis in transmitted polarized light of the thin sections was very useful. The three samples chosen belong to three different layers of plaster and they were analyzed in order to identify useful elements for their chronological placement. In detail, we analyzed: a historic plaster under the entrance (CDO 01), a plaster taken close to the reintegration (CDO 02) and a plaster taken from 
the east side (CDO 03) featuring the strong presence of ceramic elements (Fig. 5).

The CDO 01 sample has a high percentage of well-selected aggregate mainly consisting of silicate minerals (quartz and feldspar). The binder is micritic. The CDO 02 sample shows an aggregate mainly composed of quartz, very similar to the previous one, but the ratio of binder/aggregate is visibly different. The binder, always micritic and carbonatic, might be the same one used in the other Asinara towers. Finally, the CDO 03 sample probably represents the "scagliamento" mentioned in archival sources, consisting of a lime mortar with "slivers" of brick. This mortar is slightly different than the others. It has a lower quantity of aggregate and the binder, always carbonatic, is micritic and in some points microsparry.

Instead, various cladding layers of the terrace are still visible in the Trabuccato tower. Here, by looking through a hole in the dome, it was possible to determine the exact stratigraphy of the waterproofing layers. Furthermore, it could be noted how a calcareous material was used in the structural layers, at the extrados. The material is more friable and porous, and so more workable, unlike the material used for the rest of the tower (Murru, 2014).

Specifically, thin sections of two of the samples taken from the thickness of the dome were analyzed: a most superficial layer of cocciopesto (TRB01) and a mortar layer placed under the cocciopesto (TRB02).

The TRB01 sample, due to a later waterproofing intervention of the terrace, may be connected to a restoration work carried out during the second half of the 18th century described in the Archivio di Stato di Cagliari. The aggregate is very fine and comprises fragments of metamorphic rocks and few crystals. There are many brick fragments in the mixture. The binder is carbonatic, micritic, and appears microfractured. The TRB02 sample is a mortar of decent quality, although shrinkage microfractures and recrystallization of the binder may be seen. The aggregate is quite large and composed predominantly of quartz and feldspar. It is not well selected and bimodal classed. The binder, always carbonatic and micritic, is very similar to the previous mortar. The binder/aggregate ratio is low.

\section{Conclusions}

The results highlight several similarities among the three towers. This is certainly due to the use of the same materials, found on site, which influenced the level of workability and required similar masonry techniques. In fact, in all cases, the main building material is mica-schist, with elements of medium or small size, rough hewn only in the face. This material is easy to work and allows good dimensional regularity and good meshing of the masonry texture.

However, the Asinara towers also show several similar typological and architectural features as well as similar proportional relationships. This confirms our initial thesis: the imprint due to the unitary construction project was of major importance in the construction choices and binds the three towers in a common thread.

\section{Notes}

Special thanks to the Agenzia regionale Conservatoria delle Coste della Sardegna for facilitating the survey phase of this study and for financing and allowing the development of this research project.

\section{References}

Casula F. C., (2010), "Il pericolo franco-turco nel Regno di Sardegna in epoca moderna" in Contra moros y turcos, Villasimius-Baunei, September 20-24, Grafica del Parteolla, Dolianova, I, pp. 99138.

Giannattasio C., Grillo S. M., (2011), “The Mezzaspiaggia tower (Cagliari-Italy): the dating of structures by the metrological-chronological analysis of masonry and the petro-geochemical stratigraphy of building materials" in Proceedings of the $37^{\circ}$ ISA, Siena, Springer, BerlinHeidelberg, pp. 489-494. 
Giannattasio C., Grillo S. M., (2013), "On-site and laboratory investigation on the 16th-17th century masonries: The Foxi defensive tower (Sardinian Cagliari Gulf)" in Open Journal of Archaeometry, proceedings of the 38th International Symposium on Archaeometry - ISA 2010, Tampa, Florida, May 10th - 14th, PAGEPress Publications, Pavia, 1, pp. 1-10.

Giannattasio C., Grillo S. M., Vacca G., (2013), "Interdisciplinary study for knowledge and dating of the San Francesco convent in Stampace, Cagliari - Italy (XIII-XXI century)" in ISPRS Annals, XXIV International CIPA Symposium, Strasbourg, September 2-6, Copernicus Publications, II5/W1, pp. 139-144.

Giannattasio C., Grillo S. M., Murru S., (2014), “The Western Sardinian coast defensive towers (16th17th century): an interdisciplinary approach for the chronological definition of masonries" in Proceedings of 4th Annual International Conference on Architecture, July 7-10, ATINER'S conference papers series, Athens institute for education and research, Athens, pp. 3-17.

Montaldo G., (1992), Le torri costiere della Sardegna, Delfino Carlo Editore \& C., Sassari.

Murgia G., (2010), "Presenza Corsara nel Mediterraneo occidentale e problemi di difesa nel Regno di Sardegna (secoli XVI-XVII)" in Proceedings of Contra moros y turcos, Villasimius-Baunei, September 20-24, Grafica del Parteolla, Dolianova, I, pp. 155-195.

Murru S., (2013), "Cerdeña y Córsega: intercambios de saberes constructivos en la fabricación de las torres costeras" in Actas del Octavo Congreso Nacional de historia de la construcción. Madrid 9-12 de octubre de 2013, Instituto Juan de Herrera, Madrid, 2, pp. 757-766.

Murru S., (2014), "Investigating 500-year-old coastal towers in Sardinia and Corsica: a multidisciplinary research protocol" in Proceedings of ICE EHH, London, 167:2, pp. 88-99.

Pillosu, E., (1957), Le torri litoranee in Sardegna, La Cartotecnica, Cagliari.

Pisu C., Casu P., (2013), "Photo-modeling and cloud computing. Application in the survey of late gothic architectural elements" in Proceedings of $3 D$ Virtual Reconstruction and Visualization of Complex Architectures (3D-ARCH 2013), International Archives of the Photogrammetry, ISPRS, Trento, Vol. XL-5/W1, pp. 43-50.

Rassu M., (2005), Sentinelle del mare. Le torri della difesa costiera della Sardegna, Grafica del Parteolla, Dolianova. 